\title{
Association between antioxidant vitamins and asthma outcome measures: systematic review and meta-analysis
}

\author{
S Allen, J R Britton, J A Leonardi-Bee
}

\begin{abstract}
See Editorial, p 560
- Further information is published online only at http:// thorax.bmj.com/content/vol64/ issue7

Division of Epidemiology and Public Health, University of Nottingham, Nottingham, UK

Correspondence to: Dr J Leonardi-Bee, Division of Epidemiology and Public Health, Clinical Sciences Building, University of Nottingham, Hucknall Road, Nottingham NG5 1PB, UK; jo.leonardi-bee@ nottingham.ac.uk
\end{abstract}

Received 7 July 2008 Accepted 21 January 2009

\begin{abstract}
Background: Epidemiological studies suggest that dietary intake of vitamins $A, C$ and $E$ may be associated with the occurrence of asthma. A systematic review and metaanalysis was conducted in accordance with MOOSE guidelines to determine whether vitamins $A, C$ and $E$, measured as dietary intakes or serum levels, are associated with asthma.
\end{abstract}

Methods: MEDLINE, EMBASE, CINAHL, CAB abstracts and AMED (up to November 2007), conference proceedings and bibliographies of papers were searched to identify studies of asthma, wheeze or airway responsiveness in relation to intakes and serum concentrations of vitamins A, C and E. Pooled odds ratios (OR) or mean differences (MD) with $95 \%$ confidence intervals (CI) were estimated using random effects models.

Results: A total of 40 studies were included. Dietary vitamin A intake was significantly lower in people with asthma than in those without asthma (MD -182 $\mu \mathrm{g} /$ day, $95 \% \mathrm{Cl}-288$ to $-75 ; 3$ studies) and in people with severe asthma than in those with mild asthma (MD $-344 \mu \mathrm{g} /$ day; 2 studies). Lower quantile dietary intakes (OR 1.12, 95\% Cl 1.04 to $1.21 ; 9$ studies) and serum levels of vitamin $\mathrm{C}$ were also associated with an increased odds of asthma. Vitamin E intake was generally unrelated to asthma status but was significantly lower in severe asthma than in mild asthma (MD $-1.20 \mu \mathrm{g} /$ day, $95 \% \mathrm{Cl}$ -2.3 to $-0.1 ; 2$ studies).

Conclusions: Relatively low dietary intakes of vitamins A and $\mathrm{C}$ are associated with statistically significant increased odds of asthma and wheeze. Vitamin E intake does not appear to be related to asthma status.

Diet has been widely implicated in the aetiology of cardiovascular disease ${ }^{12}$ and other disorders, but the role of diet in the aetiology of respiratory diseases is less clearly defined. Over the past 15 years many observational epidemiological studies have reported associations between diet and asthma, and particularly for the antioxidant vitamins A, C and E. However, randomised controlled trials of vitamin supplementation in asthma thus far have been inconclusive. ${ }^{3-6}$ In view of this apparent inconsistency between the observational and experimental data, ${ }^{7}$ we have attempted to determine the magnitude of the overall associations of these vitamins estimated by the observational studies by carrying out a systematic review and meta-analysis to provide pooled quantitative estimates of the likely magnitude of the effect of dietary intake and blood levels of antioxidant vitamins on a range of measures of asthma and asthma severity.

\section{METHODS}

\section{Systematic review methods}

A comprehensive search of the MEDLINE (1950 to November 2007), EMBASE (1980 to November 2007), CINAHL (1982 to November 2007) and AMED (1985 to November 2007) was conducted to identify all published comparative epidemiological studies assessing the relation between antioxidant vitamins and asthma status. Search terms were selected under guidance from the Centre for Reviews and Dissemination and the Airways Group Specialist search terms. ${ }^{8}$ Reference lists from identified relevant studies and previous reviews were scanned and checked for further studies. Abstracts were identified through searching $C A B$ abstracts database (1973 to November 2007) and American Thoracic Society conferences (2003-2007). No language restrictions were applied.

The exposures of interest were measures of dietary intake or of objective levels of vitamins in body fluids of the antioxidant vitamins $\mathrm{A}, \mathrm{C}$ and $\mathrm{E}$. The primary outcome measure used was asthma (physiciandiagnosed, self-reported physician-diagnosed or defined as exercise-induced bronchospasm/constriction); secondary outcomes included wheeze, airway reactivity and asthma severity. Studies using spirometry or symptoms of cough and breathlessness as their main outcomes were excluded as these outcomes are likely to be relatively non-specific to asthma.

Two authors (SA and JL-B) reviewed the titles and then the abstracts, excluding irrelevant papers after each stage. Disagreements were resolved by discussion. The full text of the remaining papers was sought and the following exclusion criteria applied: reviews, duplicated studies, those without relevant outcomes and those in which no quantitative results or $\mathrm{p}$ values were presented, inability to source the text. Included studies were assessed for methodological quality using the NewcastleOttawa Scale for Quality Assessment (NOS). ${ }^{9}$ The median score of 6 was used to distinguish moderate and high quality studies from poorer quality studies.

\section{Statistical analysis}

Data were extracted independently by two authors (SA and JL-B). Dichotomous outcomes are presented as odds ratios (OR) with $95 \%$ confidence intervals (CI) and continuous outcomes are presented as mean differences (MD) with $95 \% \mathrm{CI}$. Conversions of biochemical units of measurement for the exposures were performed where necessary to allow for comparisons of units across studies. ${ }^{10}$ 


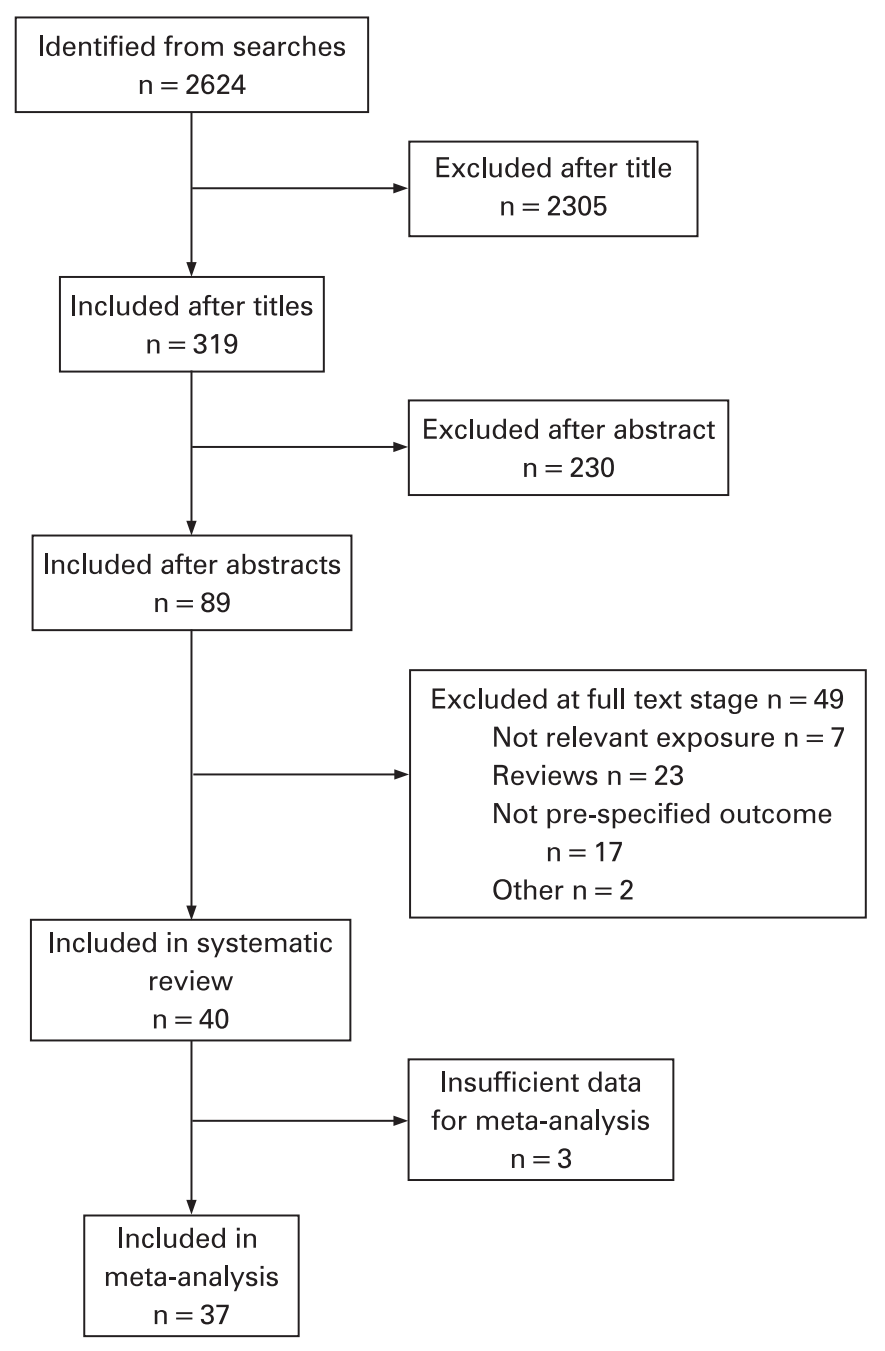

Figure 1 Flow chart for identifying studies.

Where exposure was expressed in quantiles, vitamin levels are expressed as high or low, typically representing a comparison of the lowest with the highest exposure categories.

Meta-analyses were performed to calculate weighted effect measures across studies using random effects models. Heterogeneity between the studies was assessed using $I^{2},{ }^{11}$ and if levels of heterogeneity $\left(I^{2}>75 \%\right)$ existed, then meta-analyses were not performed. Subgroup analyses relating to methods of asthma diagnosis, adult versus children and methodological quality of the studies were conducted to explore reasons for moderate levels of heterogeneity $\left(I^{2}>50 \%\right)$. Analysis was performed using Review Manager 4.2.9 (Version 4.2 for Windows, Copenhagen: The Nordic Cochrane Centre, The Cochrane Collaboration, 2003); p values $<0.05$ were considered statistically significant. The systematic review was carried out in accordance with the MOOSE guidelines. ${ }^{12}$

\section{RESULTS}

\section{Overview of included studies}

From an initial 2624 papers and abstracts identified from the literature searches, 89 had potentially eligible abstracts and 40 met the selection criteria (table 1, fig 1). Twenty-three of these assessed asthma as an outcome, ${ }^{13-35} 9$ assessed wheeze, ${ }^{36-44} 5$ assessed both asthma and wheeze, ${ }^{45-49} 2$ assessed airway reactivity ${ }^{50}$ and 1 assessed both asthma and airway reactivity. ${ }^{52}$ Twenty-six of the papers studied the effects of measures of dietary intake; ;6-19 23 $252729313234-38$ 40-45 47 49-52 23 studied biochemical levels in serum or plasma ${ }^{13-15} 17182021232426-283031333436373942464850$ and 1 assessed the effects of antioxidant levels in sputum. ${ }^{22}$ Further information about the individual studies is presented in the online supplement.

\section{Methodological quality of the studies}

The NOS scores for the 40 studies ranged from 3 to 9 , with a median of $6 ; 26$ of the 40 studies $(65 \%)$ were scored as being of moderate or high level $(\geqslant 6)$ methodological quality.

\section{Dietary intake and serum levels of vitamin A}

Overall, 21 papers reported the association of vitamin A or its components on one or more of the outcome measures, ${ }^{15-18} 242527-2931353638-40485152$ of which 11 papers assessed exposure to vitamin $A,{ }^{15-17} 1920243436394345 \quad 10$ assessed

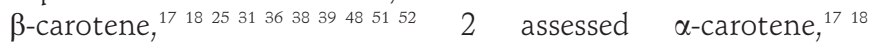
6 assessed retinol ${ }^{25} 2836405152$ and 4 assessed carotene. ${ }^{29} 313540$ The results for $\beta$-carotene, $\alpha$-carotene, retinol and carotene are presented in the online supplement.

\section{Asthma as the outcome}

Self-reported dietary intake was significantly reduced in asthma by $182 \mu \mathrm{g} /$ day $\left(95 \% \mathrm{CI}-288.42\right.$ to $-75.25 ; I^{2}=0 \%$; 3 studies; fig 2). Pooled serum levels were also reduced in asthma (4 studies; all high quality and ascertained asthma using physician diagnosis), though not to the point of statistical significance (by $0.17 \mu \mathrm{mol} / 1$ (95\% CI -0.36 to 0.02$) ; I^{2}=59 \%$; fig 2$)$. However, the direction of the association seemed to differ between adults and children, with pooled serum levels being significantly reduced in the two studies in children $(\mathrm{MD}-0.25 \mu \mathrm{mol} / \mathrm{l}$, $95 \%$ CI -0.40 to -0.10 ; fig 2 ).

\section{Asthma severity as the outcome}

Cases of severe asthma had significantly lower dietary intakes of vitamin A (MD $-344 \mu \mathrm{g} /$ day $(95 \%$ CI -575.17 to -112.64 ; $I^{2}=0 \%$; 2 studies; fig 3 ) than cases of mild disease. Results of the four studies assessing serum levels showed extreme heterogeneity $\left(I^{2}=80 \%\right)$ so a pooled analysis was not carried out; however, a subgroup analysis suggested that physiciandiagnosed cases of severe asthma (all studies of lower quality and conducted in adults) had significantly lower serum levels of vitamin $\mathrm{A}\left(\mathrm{MD}-0.48 \mu \mathrm{mol} / 1,95 \% \mathrm{CI}-0.66\right.$ to $-0.30 ; I^{2}=0 \%$; 3 studies; fig 3) than cases of mild disease. No relation was seen for self-reported severity of asthma (all conducted in children and of higher quality) ( $\mathrm{MD}-0.02,95 \% \mathrm{CI}-0.17$ to $0.13 ; 1$ study; fig 3).

\section{Wheeze as the outcome}

Although no association was seen between low dietary intakes of vitamin A and wheeze (OR $0.58,95 \%$ CI 0.29 to $1.16 ; 1$ study), low serum levels were significantly associated with a $24 \%$ decreased odds of wheeze (95\% CI 0.63 to $0.92 ; 1$ study).

Airway reactivity as the outcome

No significant associations were seen for total dietary intake of vitamin $\mathrm{A}(\mathrm{MD} 0.02,95 \% \mathrm{CI}-0.08$ to 0.12 per doubling intake). ${ }^{43}$

\section{Dietary intake and serum levels of vitamin C}

A total of 32 papers reported the association with vitamin C. ${ }^{13} 1416171921-2325$ 27-30 32-43 45-49 5152 
Table 1 Characteristics of the included studies

\begin{tabular}{|c|c|c|c|c|c|c|}
\hline Study & Design & Exposure & $\begin{array}{l}\text { Dietary component } \\
\text { measured§ }\end{array}$ & $\begin{array}{l}\text { Methodological } \\
\text { quality score* }\end{array}$ & Geographical area & Population \\
\hline Aderele $^{13}$ & Case-control & Plasma & C & 8 & Nigeria & Children \\
\hline Anetor $^{14}$ & Case-control & Serum & C & 6 & Nigeria & Adult \\
\hline Baker $^{34} \uparrow$ & Case-control & Serum, dietary & $A, C, E$ & 8 & England & Adult \\
\hline Bodner $^{36}$ & Nested case-control & Plasma, dietary & $A, C, E$ & 8 & Scotland & Adult \\
\hline Burns $^{49}$ & Cross-sectional & Dietary & $C, E$ & 5 & USA and Canada & Children \\
\hline Fogarty ${ }^{50} \phi$ & Cross-sectional & Serum, dietary & $\mathrm{E}$ & 6 & England & Adult \\
\hline Ford $^{17}$ & Cross-sectional & Serum, dietary & $A, C, E$ & 4 & USA & Adult \\
\hline Garcia-Larsen ${ }^{43}$ & Cross-sectional & Dietary & $A, C, E$ & 5 & Chile & Adult \\
\hline Gibson ${ }^{18} \uparrow$ & Case-control & Serum & A & 7 & Australia & Adult \\
\hline Grievink $^{38}$ & Cross-sectional & Dietary & $A, C, E$ & 5 & Netherlands & Adult \\
\hline $\mathrm{Hijazi}^{45}$ & Case-control & Dietary & $A, C, E$ & 7 & Saudi Arabia & Children \\
\hline Kongerud $^{22}$ & Case-control & Sputum & $C, E$ & 3 & USA & Adult \\
\hline Mainous $^{46}$ & Cross-sectional & Serum & C & 4 & USA & Adult \\
\hline Misso ${ }^{23}$ & Case-control & Serum, dietary & C & 8 & Australia & Adult \\
\hline Mizuno $^{24}$ & Case-control & Serum & $C, E$ & 7 & Japan & Children \\
\hline Murray ${ }^{40} \dagger$ & Case-control & Dietary & $A, C, E$ & 7 & England & Children \\
\hline Nagel $^{25 *}$ & Case-control & Dietary & $\mathrm{A}, \mathrm{C}, \mathrm{E}$ & 7 & Germany & Adult \\
\hline Olusi $^{26} \$$ & Case-control & Serum & C & 5 & Nigeria & Not specified \\
\hline Omenaas ${ }^{41}$ & Cross-sectional & Dietary & C & 5 & Norway & Adult \\
\hline Pate $^{35}$ & $\begin{array}{l}\text { Population-based case- } \\
\text { control }\end{array}$ & Dietary & $A, C, E$ & 8 & England & Adult \\
\hline Picado $^{27}$ & Case-control & Serum, dietary & $A, C, E$ & 7 & Spain & Adult \\
\hline Powell ${ }^{28} \dagger$ & Cross-sectional & Serum & $A, C, E$ & 6 & England & Children \\
\hline Tan-Un $n^{31}$ & Case-control & Serum, dietary & $A, E$ & 6 & China & Adult \\
\hline Troisi $^{32}$ & Cohort & Dietary & $A, C, E$ & 7 & USA & Adult \\
\hline Vural $^{33}$ & Case-control & Serum & C & 4 & Turkey & Adult \\
\hline Woods ${ }^{52}$ & Cross-sectional & Dietary & $A, C, E$ & 5 & Australia & Adult \\
\hline
\end{tabular}

*Methodological quality of studies based on the Newcastle-0ttawa Quality Assessment Scale. †Non-parametric data presented in article. $\$$ Excluded from meta-analysis due to insufficient data. §Constituent of vitamin A or E measured.

Asthma as the outcome

Low levels of dietary vitamin $\mathrm{C}$ intake were associated with a significant increase in the relative odds of asthma (OR 1.12, 95\% CI 1.04 to $1.20 ; I^{2}=0 \%$; 9 studies; fig 4). Meta-analysis of studies reporting serum vitamin $\mathrm{C}$ levels and the odds of asthma was not carried out because of extreme levels of heterogeneity ( $I^{2}=94 \%$; 2 studies; both studies were of moderate to high quality and used self-reported asthma diagnosis); however, individual studies showed that low levels of serum vitamin C were associated with increased odds of asthma (OR 1.01, 95\% CI 1.00 to 1.02 per $1 \mu \mathrm{mol} / \mathrm{l}$ increase; ${ }^{35}$ OR $1.22,95 \%$ CI 1.11 to 1.33). ${ }^{48}$

The mean dietary intake of vitamin $\mathrm{C}$ was not significantly different in people with asthma compared with those without asthma (MD $-8.62 \mathrm{mg} /$ day, $95 \% \mathrm{CI}-19.77$ to $2.53 ; I^{2}=19 \% ; 5$ studies). Pooled analyses of mean serum levels of vitamin $C$ and asthma status could not be performed owing to high levels of heterogeneity ( $I^{2}=100 \%$; 9 studies), primarily relating to one study ${ }^{14}$ in which extremely high levels of vitamin C were seen in the control group (mean $272.54 \mu \mathrm{mol} / \mathrm{l}$ ). A sensitivity analysis restricted to high-quality studies $(\mathrm{NOS} \geqslant 8$ ) excluded this finding ${ }^{14}$ and revealed that people with asthma had mean serum levels that were significantly lower (by $16.8 \mu \mathrm{mol} / 1,95 \%$ CI -21.5 to $-12.1 ; I^{2}=0 \%$; 2 studies), while non-significant reductions were seen in moderate and lower quality studies (fig 5). Subgroup analyses based on age (adult: $I^{2}=99.5 \%, 6$ studies; children: $I^{2}=84 \%, 2$ studies) and method of asthma ascertainment (physician-diagnosed: $I^{2}=88 \%, 6$ studies; selfreported: 1 study; unknown method: 1 study) indicated that these factors did not explain any of the observed heterogeneity.

Asthma severity as the outcome

Similar dietary intake (MD $-16.13 \mathrm{mg} /$ day, $95 \% \mathrm{CI}-41.02$ to $8.76, I^{2}=0 \% ; 2$ studies) and serum levels (MD $-5.41 \mu \mathrm{mol} / \mathrm{l}$, $95 \% \mathrm{CI}-14.17$ to $3.35 ; I^{2}=67 \%$; 4 studies) of vitamin $\mathrm{C}$ were seen between severe and non-severe asthma. 
Figure 2 Dietary intake ( $\mu \mathrm{g} /$ day) and serum levels $(\mu \mathrm{mol} / \mathrm{l})$ of vitamin $A$ and asthma. Mean differences relate to the difference in mean dietary intakes or serum levels of vitamin A. Squares are the difference in means between people with asthma and those without asthma, and bars represent $95 \%$ confidence intervals (Cl). Negative mean differences indicate lower levels seen in subjects with asthma than in those without asthma. Arrows on the end of bars indicate that the limits are beyond the scale presented.
Outcome: 01 Dietary intake of vitamin A ( $\mu \mathrm{g} / \mathrm{day})$ and asthma

Study Mean difference (random) Mean difference (random)

or sub-category $95 \% \mathrm{Cl}$ $95 \% \mathrm{Cl}$

01 Case control studies

Baker 1999

De Luis 2005

Picado 2001

Subtotal $(95 \% \mathrm{Cl})$

Test for heterogeneity: $\chi^{2}=0.11, \mathrm{df}=2(\mathrm{p}=0.94), \mathrm{I}^{2}=0 \%$

Test for overall effect: $Z=3.34(p=0.0008$

$\begin{array}{cccc}-1000 \quad-500 & 0 & 500 & 1000 \\ \text { Preventative factor } & \text { Risk factor }\end{array}$

$-184.00 \quad(-392.79,24.79)$

$-183.00 \quad(-307.46,-58.54)$

$55.00 \quad(-1323.04,1433.04)$

$-181.84 \quad(-288.42,-75.25)$

Outcome: $\quad 05$ Serum levels of vitamin $A(\mu \mathrm{mol} / \mathrm{l})$ and asthma

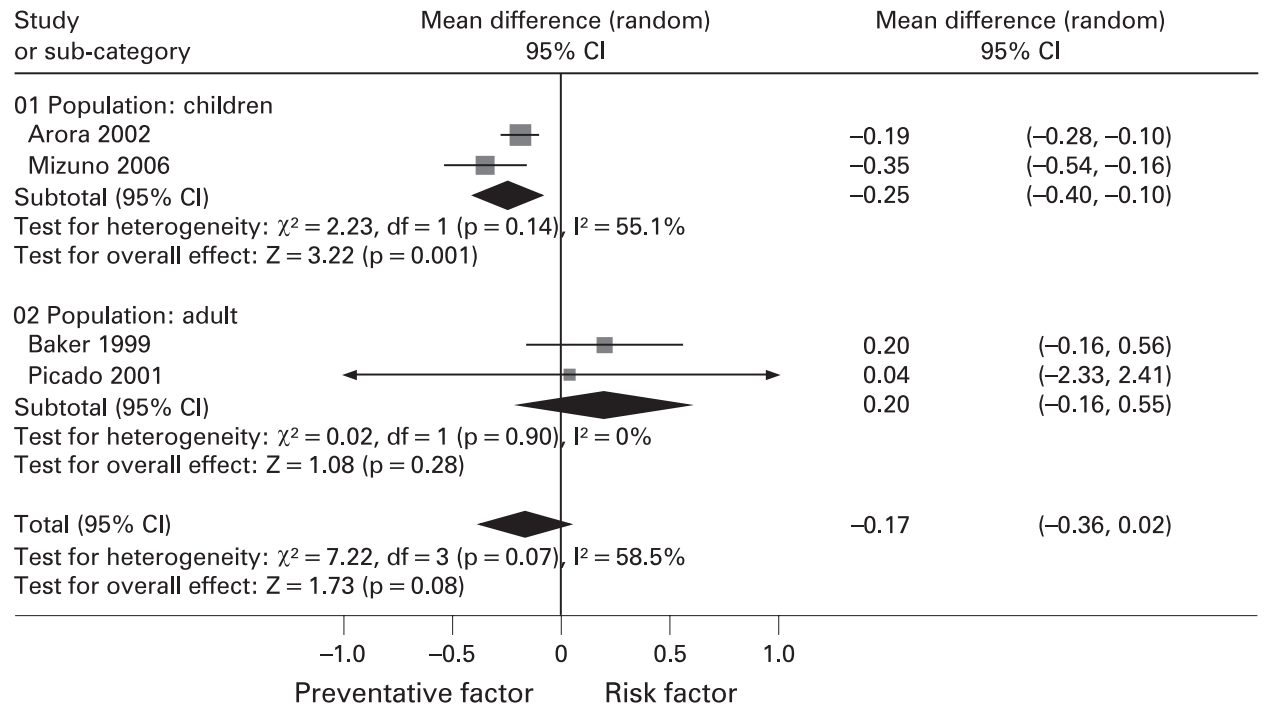

Figure 3 Dietary intake ( $\mu \mathrm{g} /$ day) and serum levels $(\mu \mathrm{mol} / \mathrm{l})$ of vitamin $A$ and asthma severity. Mean differences relate to the difference in mean dietary intakes or serum levels of vitamin A. Squares are difference in means between people with severe asthma and those without severe asthma, and bars represent $95 \%$ confidence intervals (Cl). Negative mean differences indicate that lower levels are seen in people with severe asthma than in those with mild asthma. Arrows on the end of bars indicate that the limits are beyond the scale presented.
Outcome: $\quad 03$ Dietary intake of vitamin A ( $\mu \mathrm{g} / \mathrm{day})$ and asthma severity

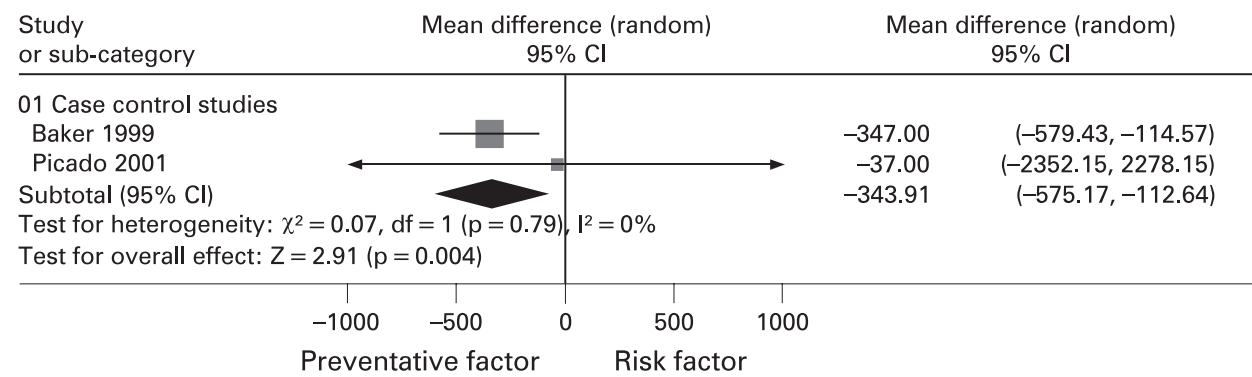

Outcome: $\quad 06$ Serum levels of vitamin $A(\mu \mathrm{mol} / \mathrm{l})$ and asthma severity

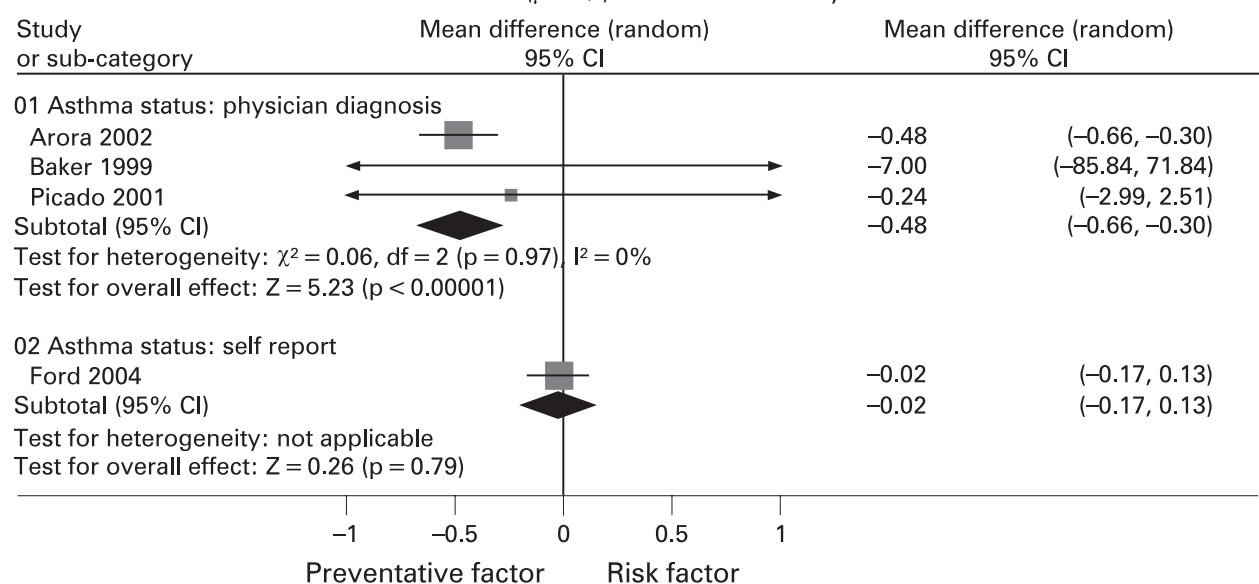


Figure 4 Dietary intakes (mg/day) of vitamin $C$ and asthma. Odds ratios relate the ratio of odds of low dietary levels of vitamin $C$ in people with asthma compared with those without, and bars represent 95\% confidence intervals (CI). 0 dds ratios $<1$ indicate that lower dietary levels of vitamin $C$ are seen in people with asthma than in those without asthma. Arrows on the end of bars indicate the limits are beyond the scale presented.
Figure 5 Serum levels $(\mu \mathrm{mol} / \mathrm{l})$ of vitamin $\mathrm{C}$ and asthma. Mean differences relate to the difference in mean serum levels of vitamin C. Squares are differences in mean between people with asthma and those without asthma and bars represent $95 \%$ confidence intervals (CI). Negative mean differences indicate that lower levels are seen in people with asthma than in those without asthma. Arrows on the end of bars indicate the limits are beyond the scale presented.
Outcome:

01 Dietary intake of vitamin C (mg/day) and asthma

Study

or sub-category

Odds ratio (random)

Odds ratio (random)

01 Case-control studies

Hijazi 2000

Patel 2006

Shaheen 2001

Subtotal $(95 \% \mathrm{Cl})$ $95 \% \mathrm{Cl}$ $95 \% \mathrm{Cl}$

Exposed group

Test for heterogeneity: $\chi^{2}=1.57, \mathrm{df}=2(\mathrm{p}=0.46), 1^{2}=0 \%$

Test for overall effect: $Z=2.84(p=0.004)$

02 Cross-sectional studies

Burns 2007

Huang 2001

Omenaas 2003

Romieu 2004a

Romieu 2004b

Woods 2003

Subtotal $(95 \% \mathrm{Cl})$

$1.79(0.86,3.70)$

$1.12(1.03,1.22)$

$1.09(0.75,1.58)$

$1.13(1.04,1.23)$

Lowest tertile

Per quintile decrease Lowest quintile

Test for heterogeneity: $\chi^{2}=5.85, \mathrm{df}=5(\mathrm{p}=0.32), 1^{2}=14.5 \%$

Test for overall effect: $Z=0.96(p=0.34)$

03 Cohort studies

Troisi 1995

Subtotal $(95 \% \mathrm{Cl})$

Test for heterogeneity: not applicable

Test for overall effect: $Z=0.44(p=0.66)$

Total $(95 \% \mathrm{Cl})$

$1.04(0.69,1.56)$

$1.82(0.88,3.77)$

$<85 \mathrm{mg}$

Lowest tertile

$0.68(0.36,1.28) \quad<56 \mathrm{mg}$

$1.59(0.91,2.77)<60 \mathrm{mg}$

$1.04(0.69,1.57)$

$<60 \mathrm{mg}$

$1.08(0.76,1.53)$

$<60 \mathrm{mg}$

$1.11(0.90,1.37)$

Per log unit decrease

$0.90 \quad(0.57,1.44)$

Lowest quintile

$1.12(1.04,1.21)$

Test for heterogeneity: $\chi^{2}=8.31, \mathrm{df}=9(\mathrm{p}=0.50), 1^{2}=0 \%$

Test for overall effect: $Z=2.90(p=0.004)$

\section{1}

$\begin{array}{cc}0.2 & 0.5 \\ \text { Decreased risk }\end{array}$

Outcome: $\quad 02$ Serum levels of vitamin $C(\mu \mathrm{mol} / \mathrm{l})$ and asthma

\begin{tabular}{lcc} 
Study & Mean difference (random) & Mean difference (random) \\
or sub-category & $95 \% \mathrm{Cl}$ & $95 \% \mathrm{Cl}$ \\
\hline
\end{tabular}

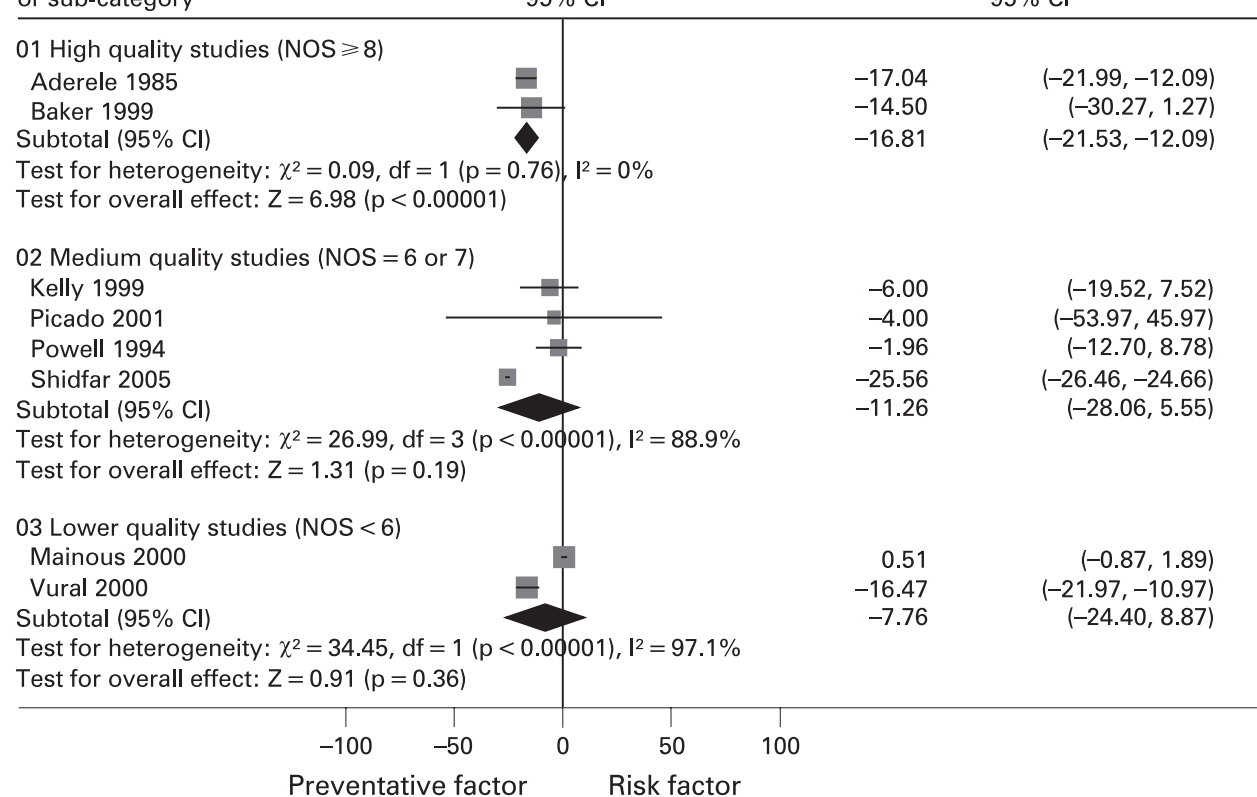


Figure 6 Dietary intake (mg/day) and serum levels $(\mu \mathrm{mol} / \mathrm{l})$ of vitamin $C$ and wheeze. Odds ratios relate the ratio of odds of low dietary intake or serum levels of vitamin C in people with wheeze compared with those without, and bars represent 95\% confidence intervals (CI). Odds ratios $<1$ indicate that lower levels of vitamin $C$ are seen in people with wheeze than in those without wheeze. Arrows on the end of bars indicate the limits are beyond the scale presented.

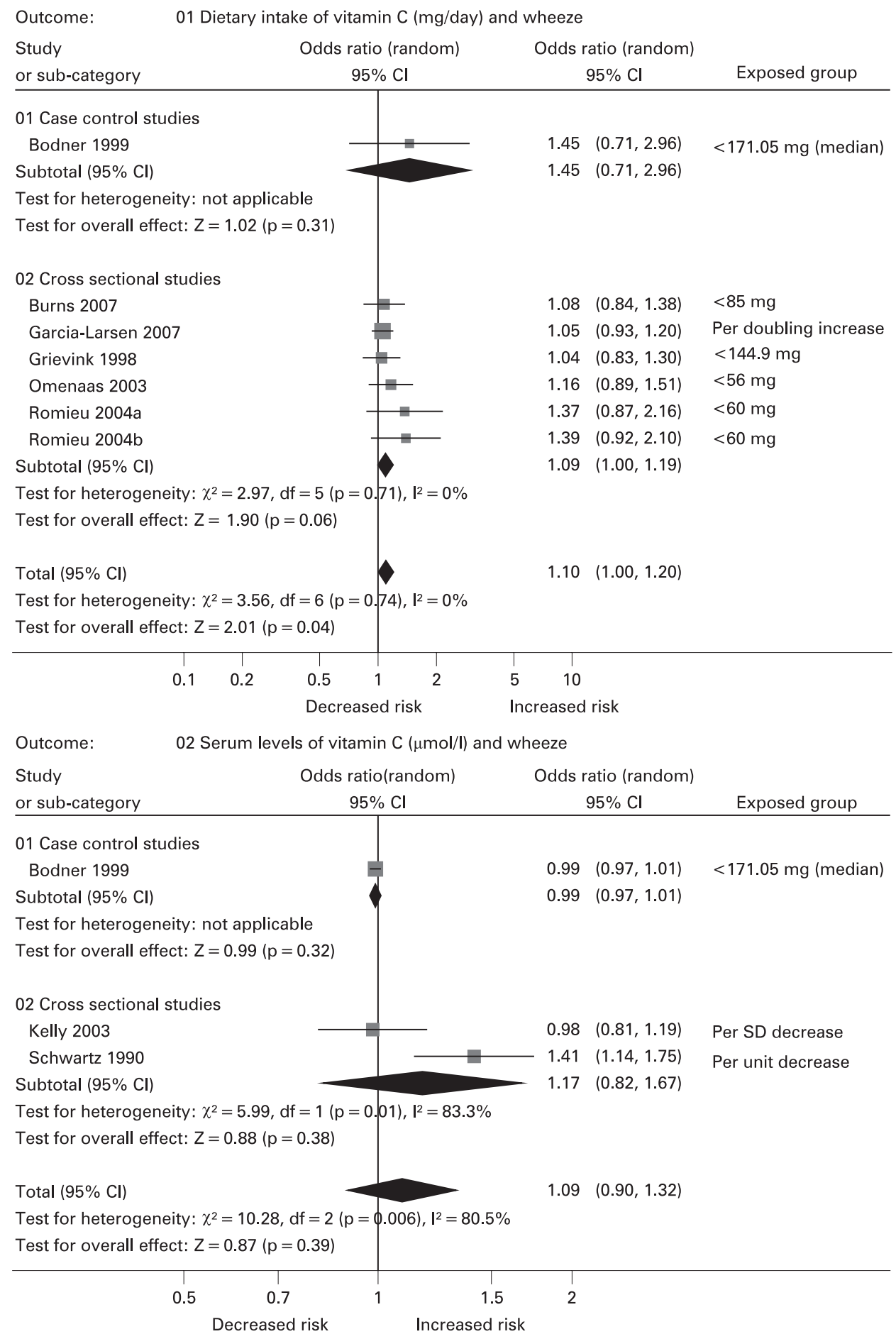

\section{Wheeze as the outcome}

An increased odds of wheeze was associated with lower dietary intakes of vitamin C (OR 1.10, 95\% CI 1.00 to $1.20 ; p=0.04$ $I^{2}=0 \%$; 6 studies; fig 6 ). Extreme levels of heterogeneity were seen between the studies that assessed serum levels of vitamin C and the odds of wheeze ( 3 studies; $I^{2}=81 \%$ ), therefore pooled analyses were not performed. All three studies were of moderate to high quality and assessed wheeze using self-reported questionnaire; however, a subgroup analysis based on age found that no effect was present in adults (OR $0.99,95 \%$ CI 0.97 to 1.01; $I^{2}=0 \% ; 2$ studies), but a significant $41 \%$ increase in the odds of wheeze was seen in the study that included participants of all ages (95\% CI 1.14 to 1.75$){ }^{42}$ Additionally, mean dietary intake (MD $4.70 \mathrm{mg} /$ day, $95 \% \mathrm{CI}-26.6$ to $36.0 ; 1$ study) and mean serum vitamin C (MD $0.06 \mu \mathrm{mol} / 1,95 \% \mathrm{CI}-1.00$ to 1.12 ; $I^{2}=0 \% ; 2$ studies) were similar in people with and without wheeze.

Airway reactivity as the outcome

Three heterogeneous studies conducted in adults ${ }^{435152}$ reported the relation between dietary intake of vitamin $\mathrm{C}$ and airway reactivity as measured using methacholine challenge. Two studies found evidence of a significant increase in airway reactivity with lower levels of vitamin C (OR 7.14; 95\% CI 1.92 
Figure 7 Dietary intakes (mg/day) and serum levels $(\mu \mathrm{mol} / \mathrm{l})$ of vitamin $\mathrm{E}$ and asthma. Mean differences relate to the difference in mean dietary intake or serum levels of vitamin E. Squares are differences in mean between people with asthma and those without asthma, and (CI). Negative mean differences indicate that lower levels are seen in people with asthma than in those without asthma. Arrows on the end of bars indicate the limits are beyond the scale presented. bars represent $95 \%$ confidence intervals

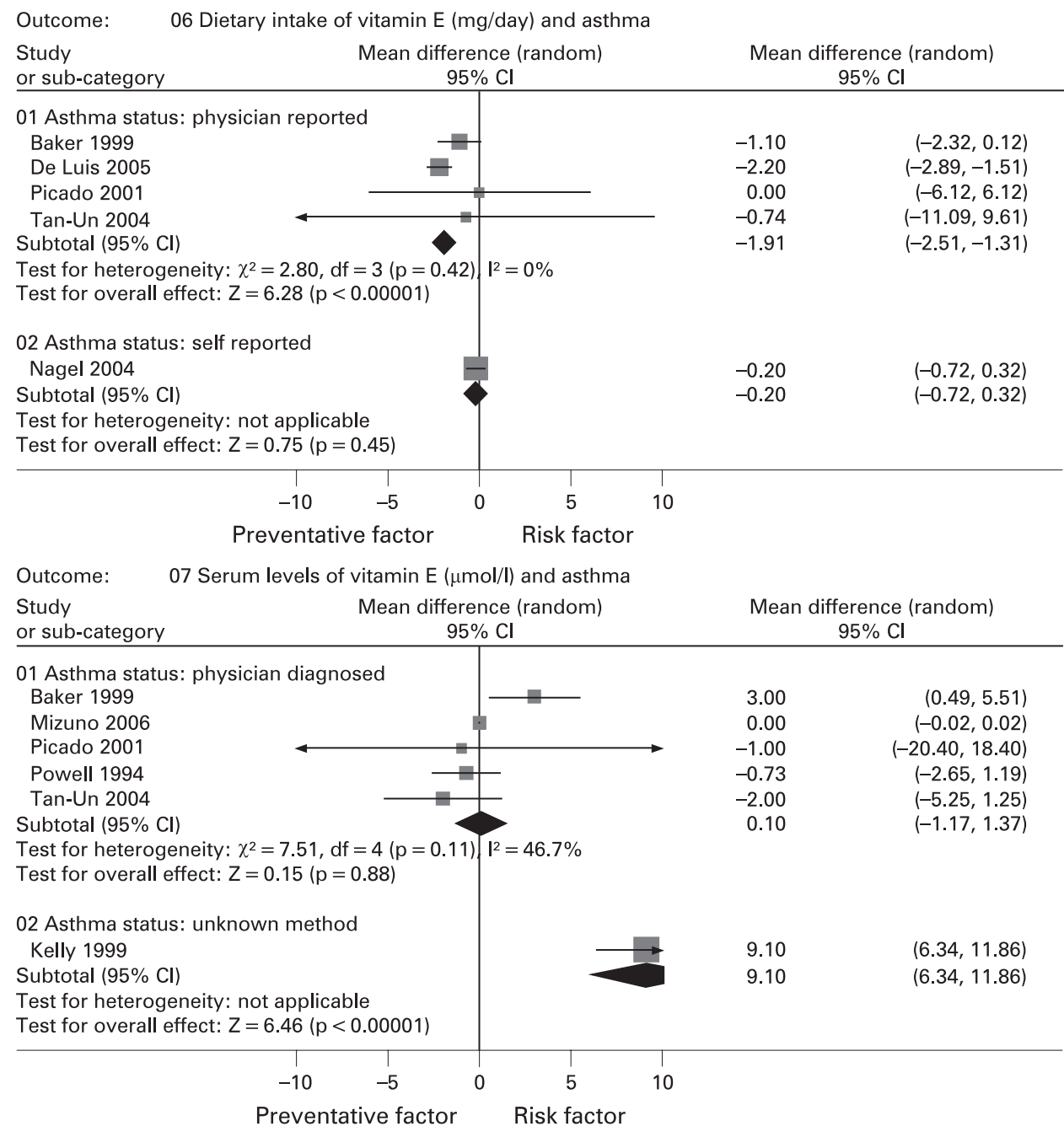

to $25.0 ;^{51} \mathrm{MD}-0.12,95 \% \mathrm{CI}-0.22$ to -0.03 per doubling in intake), ${ }^{43}$ but no association was seen in the other study (OR $1.04,95 \%$ CI 0.76 to 1.43$).^{52}$

\section{Dietary intake and serum levels of vitamin $E$}

Twenty-four studies reported the association with vitamin $\mathrm{E}$ levels, ${ }^{16} 172122242527-293132$ 34-36 38-40 43-45 48 495152 of which 4 assessed $\boldsymbol{\alpha}$-tocopherol in particular. ${ }^{21} 283136$

\section{Asthma as the outcome}

Pooled analyses could not be performed to assess the relation between mean dietary intake $\left(I^{2}=81 \%\right.$; 5 studies $)$ or mean serum levels ( $I^{2}=90 \%$; 6 studies) of vitamin E and asthma due to extreme heterogeneity. All of the studies that measured mean dietary intake of vitamin $\mathrm{E}$ were of moderate to high quality and conducted in adults, and therefore only subgroup analyses based on ascertainment of asthma status were conducted. Significantly lower mean levels of dietary vitamin $\mathrm{E}$ were associated with asthma in studies which used physician diagnoses ( $\mathrm{MD}-1.91 \mathrm{mg} / \mathrm{day}, 95 \%$ CI -2.51 to -1.31 ; $I^{2}=0 \%$; 4 studies; fig 7), however no effect was seen for self reported asthma status ( $\mathrm{MD}-0.20 \mathrm{mg} /$ day; $95 \% \mathrm{CI}-0.72$ to 0.32 ; 1 study; fig 7 ). All of the studies that measured serum levels of vitamin E were of high quality, so subgroup analyses based on age and ascertainment of asthma were conducted. Age did not explain the observed heterogeneity (adults: MD 3.12,
$95 \%$ CI -2.53 to $8.76, I^{2}=89 \%, 4$ studies; children: MD 0.00, $95 \%$ CI -0.02 to $0.02, I^{2}=0 \% ; 2$ studies), and no significant difference in mean serum vitamin $\mathrm{E}$ levels were seen with asthma in studies which used physician diagnoses (MD $0.10 \mu \mathrm{mol} / 1,95 \%$ CI -1.17 to $1.37 ; I^{2}=47 \%$; 5 studies; fig 7 ). However, significantly increased levels of vitamin $\mathrm{E}$ were seen in the study which did not define asthma status (MD $9.10 \mu \mathrm{mol} / \mathrm{l}$, 95\% CI 6.34 to 11.86; 1 study; fig 7).

No relation was seen between the odds of asthma and lower dietary intakes of vitamin E (OR $1.23,95 \%$ CI 0.90 to 1.69 ; $I^{2}=74 \%$; 6 studies) or serum levels of vitamin E (OR 1.04, 95\% CI 0.91 to $1.19 ; 1$ study). All of the studies of the relation between dietary intake of vitamin $\mathrm{E}$ and the odds of asthma (6 studies) used self-reported ascertainment of asthma. A subgroup analysis of these studies showed a non-significant trend towards an increased odds of asthma with lower levels of dietary vitamin E (adults: OR 1.25, 95\% CI 0.93 to $1.67 ; p=0.13 ; I^{2}=53 \% ; 4$ studies); however, studies were too heterogeneous for comparisons in children $\left(I^{2}=91 \% ; 2\right.$ studies $)$. A subgroup analysis based on quality of the studies did not explain any of the observed heterogeneity between the 6 studies (moderate to high quality: $I^{2}=84 \%, 3$ studies; low quality: $I^{2}=63 \%, 3$ studies).

Asthma severity as the outcome

Significantly lower dietary intake was seen in those with severe asthma $\left(\mathrm{MD}-1.20 \mu \mathrm{g} /\right.$ day, $95 \% \mathrm{CI}-2.29$ to $-0.11 ; I^{2}=0 \% ; 2$ 
studies) but there was no difference in mean serum levels (MD $-0.34 \mu \mathrm{mol} / 1,95 \%$ CI -3.79 to $2.94 ; I^{2}=31.5 \%$; 3 studies) compared with those with less severe disease.

\section{Wheeze as the outcome}

Similar levels of dietary intakes of vitamin $\mathrm{E}$ were seen in people with wheeze and those without (MD $0.80 \mu \mathrm{g} /$ day, 95\% CI -0.23 to 1.83 ; 1 study). No relation was seen between the odds of wheeze and lower serum levels (OR 1.08, 95\% CI 0.88 to 1.30 ; 1 study) or lower levels of dietary intake (OR 0.90, 95\% CI 0.68 to $1.20 ; I^{2}=66 \% ; 5$ studies).

\section{Airway reactivity as the outcome}

No association was seen between the risk of airway reactivity and lower dietary intakes of vitamin E (OR 1.06, 95\% CI 0.48 to 2.38; $I^{2}=39 \%$; 2 studies; $\mathrm{MD}-0.08,95 \% \mathrm{CI}-0.26$ to 0.09 per doubling intake; 1 study).

\section{DISCUSSION}

This systematic review and meta-analysis of the evidence on antioxidant vitamin intake and asthma status shows a consistent negative association between overall dietary vitamin A intake and the odds of asthma and severe asthma, although findings for wheeze were less consistent. The mean deficit of $182 \mu \mathrm{g}$ vitamin A per day in people with asthma relates to $26 \%$ and $30 \%$ of the latest recommended daily intakes of vitamin A for men and women, respectively. ${ }^{54}$ Additionally, most of the studies assessing the association found mean levels of vitamin A in people with asthma were below the recommended daily intakes. Vitamin A intake was lower in people with severe asthma than in those with less severe asthma by the equivalent of about half the recommended daily amount $(50 \%$ in men and $57 \%$ in women). The results for the specific types of vitamin A (retinol, $\alpha$-carotene, total carotenoids and carotene) did not generally reach statistical significance at the $5 \%$ level; however, there was a tendency for increased serum $\beta$-carotene levels to be associated with reduced odds of asthma.

For vitamin $\mathrm{C}$ we found evidence of an increase of approximately $12 \%$ in the odds of asthma associated with lower levels of intake of vitamin C. Results from individual studies also suggested that mean serum levels tended to be lower in people with asthma. These findings were generally supported by the results for wheeze and airway reactivity; however, associations with asthma severity were not conclusive. Measures of vitamin $\mathrm{E}$ were, however, generally unrelated to asthma status, although significantly lower mean dietary intakes (by approximately $2 \mathrm{mg}$ /day, about $20 \%$ of the daily recommended intake of vitamin $\mathrm{E}$ ) were seen in studies of people with physician-diagnosed asthma.

These findings contrast with those of a recent meta-analysis of published studies ${ }^{55}$ which found no significant association between dietary antioxidant intake and asthma or lung function. However, this meta-analysis searched only for studies in adults published in English language journals and listed in only one electronic database, and the meta-analyses were based on a combined outcome of asthma or wheeze. The present study was conducted with higher methodological rigor, in accordance with the MOOSE guidelines, ${ }^{12}$ used more comprehensive sources and search strategies and, where possible, validated search terms. ${ }^{856} 57$

One concern relating to our analysis is that the methods used to ascertain levels of the antioxidant vitamins (either through dietary intake, plasma and serum or sputum levels) were inconsistent over the range of the studies included. Even within a particular type of ascertainment such as food frequency questionnaires, substantial variation existed between the methods used and the periods covered by the questionnaire, some assessing dietary intake over the last 12 months and some over 6 months. In addition, due to the design of the majority of studies included in the review, the levels of antioxidant vitamins were assessed after the onset of asthma. The use of both food frequency questionnaires and of biological levels to estimate dietary intake have recognised strengths and weaknesses, but a major strength of questionnaires is that they measure typical dietary patterns over several months and, while the quantitative estimates of intake they provide are relatively imprecise, their ranking of intake is more representative ${ }^{58}$ and therefore suitable for combination in the meta-analysis of quantile effects. Biochemical levels offer the advantage of objectivity but often reflect only relatively recent intake and may also be subject to homeostatic or other metabolic or excretory influences that distort the relation between biological level and dietary intake. For example, levels of vitamin $\mathrm{C}$ in peripheral blood show relatively little variation between intakes above the minimum recommended daily intake ${ }^{59}$ and are therefore less representative of between-subject differences in intake than questionnaire measures. Thus, while dietary and serum measures are correlated for vitamin $\mathrm{A},{ }^{60}$ vitamin $\mathrm{C}^{61}$ and vitamin $\mathrm{E}^{62}$ and, in particular, strong correlations have been reported for antioxidant vitamins in people with asthma, ${ }^{61}$ these methodological differences are still likely to cause some discrepancy in the observed relations between diet and disease.

Most of the studies we analysed did not report adjusted results, so the results from our analyses are primarily based on crude estimates which were either extracted or estimated from these studies and so are subject to the unadjusted effects of confounding factors such as age, ${ }^{26}{ }^{63}$ socioeconomic status, ${ }^{13} 35$ smoking, ${ }^{36}{ }^{64}$ body mass index, ${ }^{47}$ the effects of correlated intakes of other antioxidant vitamins and, in particular for vitamin $\mathrm{E}$, the effects of total cholesterol and lipid levels. The most common factors adjusted for in the included studies were age (23 studies), sex (18 studies), smoking (active or passive, 16 studies) and social class (12 studies); only 6 studies adjusted for the effects of other antioxidant vitamins in their analyses.

Overall, our findings from this systematic review and metaanalysis indicate that low levels of vitamin $\mathrm{C}$ intake and-to a lesser extent-vitamin A are consistently associated with asthma risk to a degree that, if causal, would be sufficient to be clinically relevant. These findings are plausible, given the recognised anti-inflammatory and antioxidant actions of these vitamins. ${ }^{50}$ However, these conclusions have not been supported by the limited data available from randomised clinical trials of dietary supplementation with vitamin $\mathrm{C}$ for which a recent Cochrane review concluded that there is no appreciable effect. ${ }^{3}$ One explanation for this discrepancy would be that the observational data are systematically flawed by biases leading to spurious results from meta-analyses, ${ }^{65}$ and particularly publication bias. We attempted to minimise the effects of publication bias by performing comprehensive searches that included "grey" literature; however, we were unable to formally test for publication bias due to the small numbers of studies included in the meta-analyses. Another possibility is that the observed relation between nutrient intake and disease is not causal but arises from correlation with other causally-related nutrients or non-dietary exposures. Alternatively, the observation may reflect a causal association arising from dietary intakes during early life that tend to track into adulthood, or from more 
sustained periods of intake than have been tested in randomised trials to date. Reverse causation is also a potential explanation, particularly in severe asthma, ${ }^{34}$ but there is no evidence that this occurs in the milder disease that predominated in the studies analysed.

The epidemiological evidence thus suggests that vitamins A and $\mathrm{C}$ are linked to asthma. Epidemiological studies and metaanalyses are useful for identifying association between exposures and diseases ${ }^{65}$ but cannot reliably establish causation. Further investigations are necessary to account for the observed associations using well-designed randomised controlled trials of vitamin supplementation in asthma. Trials of vitamin C supplementation to date have been disappointing; whether the effect of vitamin A will prove more important to clinical management or whether the observed associations with diet are due to confounding effects will only be resolved by further clinical trials.

Funding: This study was internally funded by the University of Nottingham. The study sponsor had no role in the study design; in the collection, analysis, and interpretation of the data; in the writing of the report; or in the decision to submit the paper for publication.

\section{Competing interests: None.}

\section{REFERENCES}

1. Hung HC, Joshipura KJ, Jiang $\mathrm{R}$, et al. Fruit and vegetable intake and risk of major chronic disease. J Natl Cancer Inst 2004;96:1577-84.

2. He FJ, Nowson CA, MacGregor GA. Fruit and vegetable consumption and stroke: meta-analysis of cohort studies. Lancet 2006;367:320-6.

3. Ram FS, Rowe BH, Kaur B. Vitamin C supplementation for asthma. Cochrane Database Syst Rev 2004;(3):CD000993.

4. Fogarty A, Lewis SA, Scrivener SL, et al. Corticosteroid sparing effects of vitamin C and magnesium in asthma: a randomised trial. Respir Med 2006;100:174-9.

5. Pearson PJ, Lewis SA, Britton J, et al. Vitamin E supplements in asthma: a parallel group randomised placebo controlled trial. Thorax 2004;59:652-6.

6. Romieu I, Sienra-Monge JJ, Ramirez-Aguilar M, et al. Antioxidant supplementation and lung functions among children with asthma exposed to high levels of air pollutants. Am J Respir Crit Care Med 2002;166:703-9.

7. McKeever TM, Britton J. Diet and asthma. Am J Respir Crit Care Med 2004;170:725-9.

8. Arnold E, Cates C, Lasserson T, et al. Cochrane Airways Group. In: About the Cochrane Collaboration (Cochrane Review Groups (CRGS). 2003, Issue 4.

9. Wells G, Shea B, O'Connell D, et al. The Newcastle-Ottawa Scale (NOS) for assessing the quality of nonrandomised studies in meta-analyses. http://www.ohri. $\mathrm{ca} /$ programs/clinical_epidemiology/oxford.htm (accessed 18 Feb 2009).

10. Wheaton DH, Hoffman DR, Locke KG, et al. Biological safety assessment of docosahexaenoic acid supplementation in a randomized clinical trial for X-linked retinitis pigmentosa. Arch Ophthalmol 2003;121:1269-78.

11. Higgins JP, Thompson SG. Quantifying heterogeneity in a meta-analysis. Stat Med 2002;21:1539-58.

12. Stroup DF, Berlin JA, Morton SC, et al. Meta-analysis of observational studies in epidemiology: a proposal for reporting. Meta-analysis Of Observational Studies in Epidemiology (MOOSE) Group. JAMA 2000;283:2008-12.

13. Aderele WI, Ette SI, Oduwole 0, et al. Plasma vitamin C (ascorbic acid) levels in asthmatic children. Afr J Medicine Med Sci 1985;14:115-20.

14. Anetor JI, Ajose $0 \mathrm{~A}$, Ige 0 , et al. Antioxidant status of adult Nigerian asthmatics: implications for prognosis. Nutr Health 2003;17:221-9.

15. Arora P, Kumar V, Batra S. Vitamin A status in children with asthma. Pediatr Allergy Immunol 2002:13:223-6.

16. De Luis DA, Armentia A, Aller R, et al. Dietary intake in patients with asthma: a case control study. Nutrition 2005;21:320-4.

17. Ford ES, Mannino DM, Redd SC. Serum antioxidant concentrations among U.S adults with self-reported asthma. J Asthma 2004;41:179-87.

18. Gibson PG, Wood LG, Blake R, et al. Induced sputum and circulating levels of carotenoids in asthma and healthy controls. San Diego: American Thoracic Society, 2005:abstract D16

19. Huang SL, Pan WH. Dietary fats and asthma in teenagers: analyses of the first Nutrition and Health Survey in Taiwan (NAHSIT). Clin Exp Allergy 2001;31:1875-80.

20. Kalayci $\mathbf{0}$, Besler T, Kilinc K, et al. Serum levels of antioxidant vitamins (alpha tocopherol, beta carotene, and ascorbic acid) in children with bronchial asthma. Turkish J Pediatr 2000;42:17-21.

21. Kelly FJ, Mudway I, Blomberg A, et al. Altered lung antioxidant status in patients with mild asthma. Lancet 1999;354:482-3.

22. Kongerud J, Crissman K, Hatch G, et al. Ascorbic acid is decreased in induced sputum of mild asthmatics. Inhalat Toxicol 2003;15:101-9.
23. Misso NL, Brooks-Wildhaber J, Ray S, et al. Plasma concentrations of dietary and nondietary antioxidants are low in severe asthma. Eur Respir J 2005:26:257-64.

24. Mizuno Y, Furusho T, Yoshida A, et al. Serum vitamin A concentrations in asthmatic children in Japan. Pediatr Int 2006:48:261-4.

25. Nagel G, Linseisen J. Dietary intake of fatty acids, antioxidants and selected food groups and asthma in adults. Eur J Clin Nutr 2005;59:8-15.

26. Olusi So, Ojutiku 00, Jessop WJ, et al. Plasma and white blood cell ascorbic acid concentrations in patients with bronchial asthma. Clin Chim Acta 1979:92:161-6.

27. Picado C, Deulofeu R, Lleonart R, et al. Dietary micronutrients/antioxidants and their relationship with bronchial asthma severity. Allergy 2001;56:43-9.

28. Powell CV, Nash AA, Powers HJ, et al. Antioxidant status in asthma. Pediat Pulmonol 1994;18:34-8.

29. Shaheen SO, Sterne JA, Thompson RL, et al. Dietary antioxidants and asthma in adults: population-based case-control study. Am J Respir Crit Care Med 2001;164:1823-8.

30. Shidfar F, Baghai N, Keshavarz A, et al. Comparison of plasma and leukocyte vitamin $\mathrm{C}$ status between asthmatic and healthy subjects. East Med Health $\mathrm{J}$ 2005:11:87-95.

31. Tan-Un KC, Chang KR, Chan-Yeung MMW. Use of a food frequency questionnaire on Chinese diet to assess antioxidant status in individuals with asthma. Nutr Res 2004:24:509-19.

32. Troisi RJ, Willett WC, Weiss ST, et al. A prospective study of diet and adult-onset asthma. Am J Respir Crit Care Med 1995;151:1401-8.

33. Vural H, Uzun K. Serum and red blood cell antioxidant status in patients with bronchial asthma. Can Respir J 2000;7:476-80.

34. Baker JC, Tunnicliffe WS, Duncanson RC, et al. Dietary antioxidants and magnesium in type 1 brittle asthma: a case control study. Thorax 1999;54:115-8.

35. Patel BD, Welch AA, Bingham SA, et al. Dietary antioxidants and asthma in adults Thorax 2006:61:388-93.

36. Bodner C, Godden D, Browns K, et al. Antioxidant intake and adult-onset wheeze: a case-control study. Eur Respir J 1999;13:22-30.

37. Cook DG, Carey IM, Whincup PH, et al. Effect of fresh fruit consumption on lung function and wheeze in children. Thorax 1997;52:628-33.

38. Grievink L, Smit HA, Ocke MC, et al. Dietary intake of antioxidant (pro)-vitamins, respiratory symptoms and pulmonary function: the MORGEN study. Thorax 1998:53:166-71.

39. Kelly Y, Sacker A, Marmot M. Nutrition and respiratory health in adults: findings from the health survey for Scotland. Eur Respir J 2003;21:664-71.

40. Murray CS, Simpson B, Kerry G, et al. Dietary intake in sensitized children with recurrent wheeze and healthy controls: a nested case-control study. Allergy 2006;61:438-42.

41. Omenaas $\mathbf{E}$, Fluge 0 , Buist $A S$, et al. Dietary vitamin $C$ intake is inversely related to cough and wheeze in young smokers. Respir Med 2003;97:134-42.

42. Schwartz J, Weiss ST. Dietary factors and their relation to respiratory symptoms The Second National Health and Nutrition Examination Survey. Am J Epidemio 1990;132:67-76.

43. Garcia-Larsen V, Chinn S, Arts ICW, et al. Atopy, wheeze and broncial responsiveness in young Chilean adults. Do dietary antioxidants matter? Allergy 2007:62:714-5

44. Salam MT, Gilliland FD. Dietary fat and antioxidant vitamins and respiratory symptoms in children. San Francisco: American Thoracic Society, 2007:A272.

45. Hijazi N, Abalkhail B, Seaton A. Diet and childhood asthma in a society in transition: a study in urban and rural Saudi Arabia. Thorax 2000;55:775-9.

46. Mainous AG III, Hueston WJ, Connor MK. Serum vitamin C levels and use of health care resources for wheezing episodes. Arch Fam Med 2000:9:241-5.

47. Romieu I, Mannino DM, Redd SC, et al. Dietary intake, physical activity, body mass index, and childhood asthma in the Third National Health and Nutrition Survey (NHANES III). Pediatr Pulmonol 2004;38:31-42.

48. Rubin RN, Navon L, Cassano PA. Relationship of serum antioxidants to asthma prevalence in youth. Am J Respir Crit Care Med 2004:169:393-8.

49. Burns JS, Dockery DW, Neas LN, et al. Low dietary nutrient intake and respiratory health in adolescents. Chest 2007:132:238-45.

50. Fogarty A, Britton J. The role of diet in the aetiology of asthma. Clin Exp Allergy 2000; 30:615-27.

51. Soutar A, Seaton A, Brown K. Bronchial reactivity and dietary antioxidants. Thorax 1997:52:166-70

52. Woods RK, Walters EH, Raven JM, et al. Food and nutrient intakes and asthma risk in young adults. Am J Clin Nutr 2003;78:414-21.

53. Asher MI, Keil U, Anderson HR, et al. International Study of Asthma and Allergies in Childhood (ISAAC): rationale and methods. Eur Respir J 1995;8:483-91.

54. British Nutrition Foundation. Nutrition basics: nutrient requirements and recommendations. British Nutrition Foundation, 2004. http://www.nutrition.org.uk/ home. asp? siteld $=43$ \&sectionld $=414$ \&subSectionld $=320$ qparentSection $=$ 299\&which=1\#1008 and http://www.nutrition.org.uk/upload/DRVs.pdf (accessed 18 Feb 2009).

55. Gao J, Gao X, Li W, et al. Observational studies on the effect of dietary antioxidants on asthma: a meta-analysis. Respirology 2008;13:528-36.

56. Glanville J, Lefebvre C. Identifying systematic reviews: key resources. ACP J Club 2000;132: A11-2

57. McKibbon KA. Using 'best evidence' in clinical practice. ACP J Club 1998;128:A15

58. Willett W. Nutritional epidemiology. New York: Oxford University Press, 1990. 
59. Department of Health. Dietary reference values for food energy and nutrients for the United Kingdom. Report on Health and Social Subjects (41). London: HMSO, 1991.

60. Roidt L, White E, Goodman GE, et al. Association of food frequency questionnaire estimates of vitamin A intake with serum vitamin A levels. Am J Epidemiol 1988;128: 645-54.

61. Bodner $\mathbf{C H}$, Soutar A, New SA, et al. Validation of a food frequency questionnaire for use in a Scottish population: correlation of antioxidant vitamin intakes with biochemical measures. J Human Nutr Dietetics 1998:11:373-80.
62. Willett WC, Stampfer MJ, Underwood BA, et al. Validation of a dietary questionnaire with plasma carotenoids and alpha-tocopherol levels. Am J Clin Nutr 1983;38:631-9.

63. Eagan TML, Bakke PS, Eide GE, et al. Incidence of asthma and respiratory symptoms by sex, age and smoking in a community study. Eur Respir J 2002;19:599-605.

64. Schectman G, Byrd JC, Gruchow HW, The influence of smoking on vitamin C status in adults. Am J Public Health 1989;79:158-62.

65. Egger M, Schneider M, Davey Smith G. Meta-analysis spurious precision? Metaanalysis of observational studies. BMJ 1998:316:140-4.

\section{Lung alert}

\section{Safety and effectiveness of home-based pulmonary rehabilitation in COPD}

Despite overwhelming evidence to suggest that pulmonary rehabilitation improves health status in patients with chronic obstructive pulmonary disease (COPD), this service is largely underutilised due to poor accessibility. This Canadian multicentre randomised study was designed to compare outpatient pulmonary rehabilitation with self-monitored home-based rehabilitation in improving dyspnoea.

Patients with stable COPD (forced expiratory volume in $1 \mathrm{~s}<70 \%$ predicted) and an MRC dyspnoea score of 2 or more were recruited. 252 patients with similar baseline characteristics were randomly assigned to both groups. Both groups showed statistically and clinically significant improvements in dyspnoea scores (on chronic respiratory questionnaire) at 3 months. Although this was not maintained, the home rehabilitation group was certainly not inferior to the outpatient rehabilitation group at 1 year. Both strategies were similar at 3 months and 1 year in improving 6-minute walking distance, cycling endurance time and health status (as assessed by St George's Respiratory Questionnaire components). Adverse events were comparable for both groups.

The authors conclude that home-based rehabilitation is safe and not inferior to hospital outpatient rehabilitation in improving dyspnoea, health status and exercise tolerance. They also point out that, despite the fact that no economic analysis was done, the cost implications are likely to be similar for both strategies. However, the results have to be applied cautiously in patients with severe COPD who potentially may benefit the most from home-based rehabilitation, as only a small proportion with severe disease were included in the study. This study alludes to a potential alternative for patients who are unable to access hospital-based pulmonary rehabilitation.

- Maltais F, Bourbeau J, Shapiro S, et al. Effects of home-based pulmonary rehabilitation in patients with chronic obstructive pulmonary disease. Ann Intern Med 2008;149:869-78.

\section{A Dushianthan}

Correspondence to: Dr A Dushianthan, Specialist Registrar, Morriston Hospital, Swansea, UK; dushianthan@tiscali.co.uk 